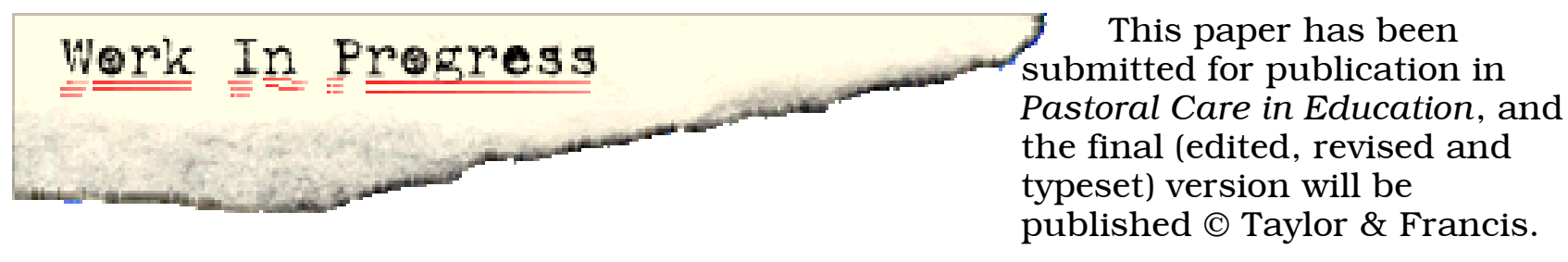

\title{
Affiliation to school: measures and interventions
}

\author{
Chris Watkins,
}

Emeritus Reader, University of London Institute of Education

Life member, National Association for Pastoral Care in Education

Chris Watkins was first a form tutor and maths teacher in 1971, and then trained in schools counselling with Douglas Hamblin. From there he moved to the University of London Institute of Education, and initiated courses in Pastoral Care. He was on the founding Executive of NAPCE in 1982 and was Chair of the Association from 1992 to 1994. Publications are on his web-site Chriswatkins.net.

\section{Abstract}

The degree of affiliation which pupils develop towards their schools is an important factor in their engagement and success. It has also been a matter of concern at the time of transfer from primary to secondary school. This article describes the development of a brief method for identifying the degree of affiliation which pupils feel, and also identifying any points of concern. Data from 670 pupils in a London secondary school is reported. Concerns about pupils' experience of transfer are often addressed through interventions which are teacher-centred. An account is given of a pupil-centred intervention to improve affiliation, and its apparent longlasting effects. 


\section{The Concept of Affiliation, its dimensions and correlates}

Human beings affiliate towards a diverse range of things: towards each other, towards ideas, and perhaps towards the organisations they spend time in. When we affiliate to an organisation, as pupils may do to a school, we mainly affiliate to persons, and through them to other relational matters such as goals and purposes. Affiliating to an organisation means to feel a sense of membership, a sense of belonging and to feel a part of something larger, as one may do with a range of communities at other levels.

Affiliation contrasts with other concepts which are sometimes confused with it. For example, the concept of identification: this could develop through a more passive uncritical process, even exploited by those who have little respect for people's choice and agency. By contrast the notion of affiliation indicates a positive and respectful notion, and indicates an aware process which other players in an organisation (in this case teachers) could seek to engage with and increase. Additionally, feeling a sense of membership with an organisation must be sensed without feeling that one has been taken over or "owned" by the organisation. Approaches to conceptualising affiliation have varied, as have the methods of measurement. Some writers and researchers take the view introduced above, and therefore focus their attention on pupils' self-report of feeling part of a school, and their relations with key people. A contrasting approach is worth noting: in USA a "National Survey of Student Engagement" defines in advance the educational activities which link to "valued educational outcomes" and then focuses attention on students' self-report of engagement in these activities (Kuh, 2001). With predefined measures and the audit culture, this "measure and display" approach leads to student responses being posted on college web-sites as part of marketing. The purpose in the work reported here is an "enquire and communicate" approach, in which data is used to present students' voices and communicate it to teachers with the intent of improving communications and then to improving school practices. 
An early study of pupils' affiliation to school was undertaken by Goodenow (1992), who took the sense of belonging and membership in school to be reflected in pupils' reports of perceived liking, personal acceptance, and inclusion; respect for and encouragement of participation; and the perceived responses of other students. Her "Psychological Sense of School Membership Scale" composed five areas of affiliation: belongingnesss, acceptance, respect, inclusion, and support (Goodenow, 1993a)

A small number of studies have shown that affiliation to school is associated with important aspects of education. Goodenow (1992) found that "a student's subjective sense of belonging appears to have a significant impact on several measures of motivation and on engaged and persistent effort in difficult academic work" in a group of 301 junior high school students. Goodenow and Grady (1993) extended this analysis, showing that school sense of membership was associated with pupils' expectancy of success, their valuing of schoolwork, general school motivation, and self-reported effort. These motivation-related measures were more associated with the sense of belonging to school than they were with their friends' valuing of school, thereby challenging the folk theory of "peer pressure" as most influential.

Hagborg (1998) found, consistent with the above, that in 120 middle school students, those with higher sense of school membership reported higher grades, more time spent on homework, and greater school motivation together with a more internal locus of control (i.e. a sense that success was more in their hands than in the hands of others).

The felt characteristics of school must play a part in affiliation to school. Roeser, Midgley and Urdan (1996) found that with a group of 296 middle school students, perceiving positive teacher-student relationships predicted positive school-related feelings, and this relation was mediated through feelings of school belonging. Sense of school belonging was also positively related to academic grades. However those students who perceived a focus on learning and improving their competence had 
stronger associations than those students who perceived a focus on performance and proving their competence.

The above studies have focused on pupils' self report of affiliation to school and its relation with individual pupils' motivation and school achievement. However, it is also possible to study school and other differences, and explore the possibility that pupil affiliation may be stronger in some social groups, some schools, and some countries.

Voelkl (1996), with a group of 3,539 pupils in USA showed that female students exhibited higher sense of school belonging with school than did their male peers. African American students identified more with school than did white students. Voelkl (1997) with a group of 1,335 students found that the higher levels of affiliation of African-American students were not attributable to prior academic achievement, but suggested that students' participation in school was crucial. Using the views of 32078 pupils from the WHO international survey Health Behaviour in School-Aged Children (Aarö et al., 1986) Samdal and colleagues (1999) suggested that "the most important psychosocial school setting predictors of students' perception of their academic achievement are that they feel satisfied with school, that they feel the teachers do not expect too much of them, and that they have a good relationship with their fellow students". They found this association to be higher amongst schoolchildren in Finland and Norway than in Latvia and Slovakia.

On the widest scale, the OECD (2001) "PISA" survey of nationally representative samples in 42 countries, asked 224,058 15-year-olds in 8,364 schools to respond to "My school is a place where I feel like I belong". $79 \%$ affirmed this statement, but country differences ranged from France (44\%) Spain (52\%) and Belgium (53\%) to Australia (85\%) Finland (86\%) and Hungary (89\%). In any one country, the picture was not uniform across schools: "In nearly every country, there is a wide range among schools in the prevalence of students considered to have a low sense of belonging and low participation" (Willms, 2003 page 54). This variation is not 
explained by "family background" of students but suggests aspects of school policy and practice that contribute to the success of schools in reducing student disaffection.

The above evidence confirms the value of focusing on affiliation to school as one element in helping a wider range of students succeed in what school life offers them. Note, however, that it does not address the crucial elements of the quality of the learning experience which school offers. Indirect evidence is offered by Lee and Smith (1993) who found that levels of student engagement were modestly influenced by school restructuring - heterogeneous grouping, team teaching and reducing the extent to which schools are organised by subject-area departments. In a study of 66012 year-olds, Anderman and Anderman (1999) found that those who perceived their classes to be about learning and improving competence reported an increase in sense of school belonging, whereas those who perceived their classes to be about performance and proving competence reported a decrease. This offers part of the explanation for classrooms as learning communities getting better results (Watkins, 2005). As they moved across the transition between schools, these students perceived their classrooms as becoming more the latter orientation.

\section{Measures}

Goodenow (1993) developed an 18-item "Psychological Sense of School Membership" scale. From the standpoint of traditional psychometric assumptions, this scale was evaluated as having good internal consistency and reliability. Hagborg (1994) confirmed the reliability, and later (1998) showed higher internal consistency with a shortened version.

In order to have a brief inquiry format which was accessible to 11 year-old pupils in a West London context, the number of items was reduced from 18 to 12 , maintaining those which represent different dimensions of the overall construct, and the language terms were localized. In addition to the scale format, it was felt very important to hear pupils' voice in a less constrained way, so on the reverse of the scale were two prompt questions and plenty of space for free-response writing: 
We're interested in your views about being at School.

There aren't any "right” or "wrong” answers.

Can you tell us how much you feel part of the school?

First of all, please respond to these statements

For each of the statements, put a tick in one of the columns on the right, to show whether you feel the statement is true. You might think it's:

a....not at all true, b....sometimes true, c....often true, d....completely true

\begin{tabular}{|c|c|c|c|c|c|}
\hline & & $\mathrm{a}$ & $\mathrm{b}$ & $\mathrm{c}$ & $\mathrm{d}$ \\
\hline 1 & I feel like a real part of ........ School & & & & \\
\hline 2 & People here notice when I'm good at something & & & & \\
\hline 3 & It is hard for people like me to be accepted here & & & & \\
\hline 4 & $\begin{array}{l}\text { Other students in this school take my opinions } \\
\text { seriously }\end{array}$ & & & & \\
\hline 5 & $\begin{array}{l}\text { Most teachers at ......... School are interested in } \\
\text { me }\end{array}$ & & & & \\
\hline 6 & Sometimes I feel as if I don't belong here & & & & \\
\hline 7 & $\begin{array}{l}\text { There's at least one teacher or other adult in } \\
\text { this school I can talk to if I have a problem }\end{array}$ & & & & \\
\hline 8 & People at this school are friendly to me & & & & \\
\hline 9 & $\begin{array}{l}\text { I am treated with as much respect as other } \\
\text { students }\end{array}$ & & & & \\
\hline 10 & I feel very different from most students here & & & & \\
\hline 11 & The teachers here respect me & & & & \\
\hline 12 & I feel proud of belonging to ........ School & & & & \\
\hline
\end{tabular}

Second, please tell us in your own words

In the time that you have been here, what things have helped you MOST to feel a part of School?

Write your idea here.

What would help you feel MORE a part of School?

Write your idea here, and discuss it with some other people in your tutor group if that would help. 
For the scale, a single score is created by allocating the following values: not at all true $=0$, sometimes true $=1$, often true $=2$, and completely true $=3$ (except for the "reverse value items: number 3, 6, and 10, where responses were given a minus value). For each individual, these items were summed across the twelve items, giving a total which could theoretically range from -9 to +27 .

The survey was first completed in the context of an "Education Action Zone" of primary and secondary schools in North-West Ealing. One of the concerns for these schools is a "dip" in measured pupil performance associated with the in the transition from primary to secondary school, One part of the project's activity was framed as a target:

"At the end of their first year in School, students will show significant increase in their affiliation to the organisation, as measured by the Sense of School Membership scales”

\section{Results from the affiliation scale}

For stage one, all Year 7 pupils in the secondary school completed the enquiry. 246 completed responses were received, covering nearly all pupils in the nine Year 7 tutor groups. Each pupils' scores were calculated, giving the distribution in Figure 1.

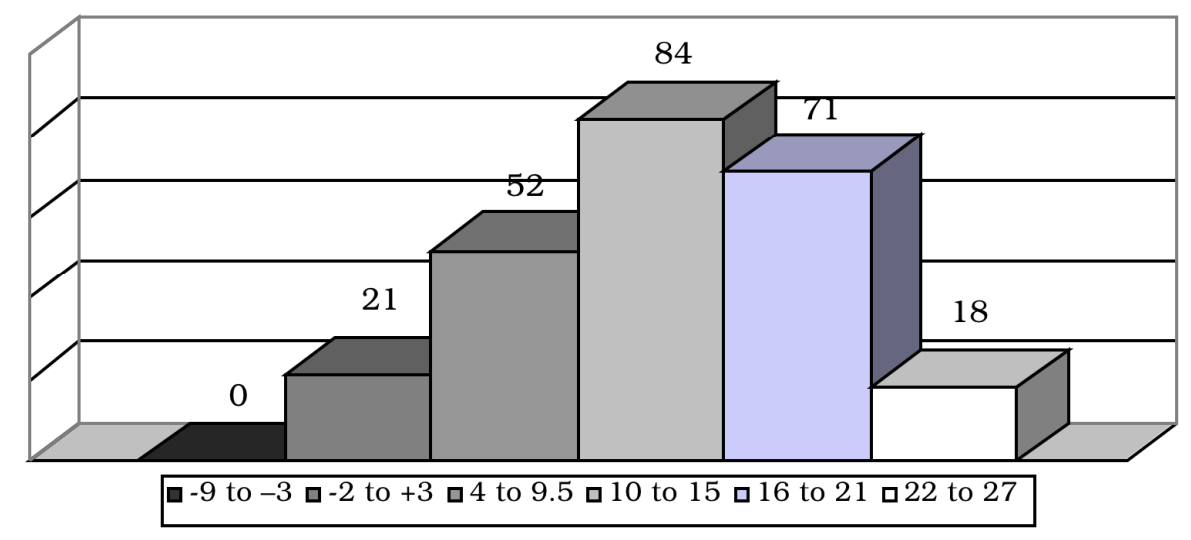

Figure 1 Total affiliation scores of 246 Year 7 pupils

There was not a set of "norms" against which to compare the results from this school against results from elsewhere. Discussion with Year 7 tutors led to the 
impression that the broad picture is generally healthy, since the distribution of scores is biased towards the higher end. The average score for the whole year group is +1.75 , which is equivalent to saying that pupils rate as "often true" positive items about feeling part of the school. At the same time there is cause for concern. Although no students scored in the very negative range, 21 students scored very low and thus indicate that they do not feel part of the school. Different dimensions of the sense of school membership were analysed. Average scores for the five underlying dimensions were: Acceptance: 1.71; Belongingness: 2.02; Inclusion: 1.95; Respect: 1.51; Support: 1.59. It could not be assumed that different dimensions have the same "value" behind them, but these figures could alert us to the possibility that the school had done well on belongingness, inclusion and acceptance, but a little less well on respect and support.

Scores were also analysed by Tutor Group. The average total score for each tutor group is shown in Figure 2.

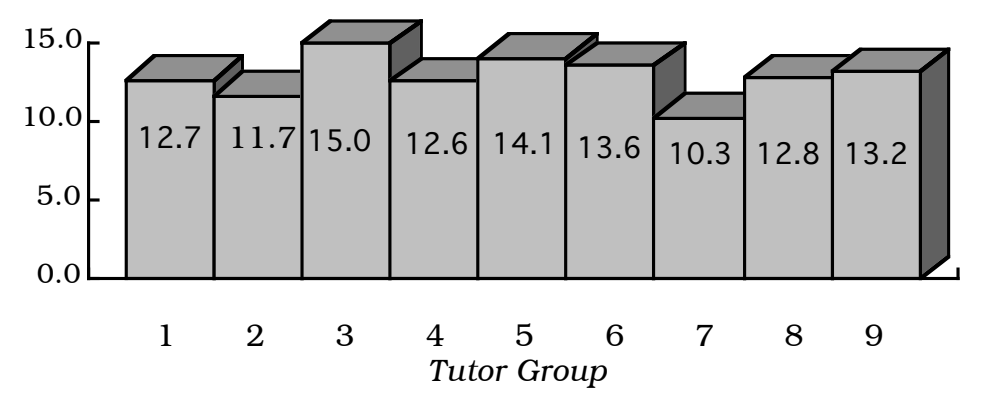

Figure 2: Total affiliation scores for 246 Year 7 pupils, by tutor group

The difference between these scores by tutor group seemed significant. Tutors felt that the tutor group 3 with a score of 15.0 seemed well-connected to school while the group 7 with a score of 10.3 seemed significantly at risk. It was accepted that such groups will develop differently for a wide range of reasons: their composition and individual histories, their establishment and career in the new school, their experience and possible reputation effects. But this analysis raised the possibility that the group was an important locus for the development of affiliation, especially in the context where some of the teaching is in tutor groups. 
Results from the free-response writing

Most pupils gave a response in this section.. In terms of what helped most, three aspects were mentioned very frequently:

- Having friends I already know in my form

- My form tutor

- The teachers

These were followed by less frequent but still regular mention of:

- Family, sisters, brothers, etc

- Having friends in other years

- Making new friends

- After school clubs

- Wearing the school uniform

- Being treated like everyone else

And occasional mention of :

- The tour on the first day

- The dinner ladies

- Joining a sports team

Verbatim comments included:

"I feel much older than before"

"The helpful people made me feel all warm and tingly inside"

"Mr. X is the best teacher anybody could have"

In terms of what would help more, the most frequent response was:

- Older pupils being more helpful, not barging, not treating us unkind

Other regular mentions were:

- More friends from my junior school in my tutor group

- More clubs (some just for Year 7)

- Running our own club, having a disco/party

- If people didn't say "little year 7" 
And occasional mention of :

- Not so many detentions

- Representing the school

- Making sure everybody's ideas gets in

- A water fountain

Verbatim comments included:

"for people to take me how I am, not how I look"

"It would help if some of the teachers didn't pick on me because of my reputation at my old school"

"It would help if I knew more about people"

The school had a long-standing and valued practice of taking Year 7 pupils on a "camp" in the summer term. Many staff reported that this intervention had, in their view, significant effects on pupils' affiliation to school. Accordingly the Year 7 tutor team asked whether the survey could be repeated in July so that pupils' scores could be compared. On this occasion 226 completed responses were received. The scoring and analysis of the whole year group seemed to produce a picture which was slightly improved. The mean score in October had been 12.9, and in July it was 13.0. Staff were aware that the trend in the secondary school could be one of disaffiliation. The Head and staff were pleased that there was at minimum evidence that such a trend was not occurring here.

\section{Interventions for effective transition}

Three decades ago, Watkins (1983) noted three different stances on the focus to be adopted for successful transition from primary school to secondary school:

- Curriculum Continuity

- Communicating Information on Pupils

- Preparation and Induction 
These three stances remain two decades later. DfES "transition units" seemed to focus only on aspect: the detail of the planned curriculum, and as an intervention run the risk of being "more of the same". Many primary and secondary schools spend valuable time communicating various data on pupils, but often quietly acknowledge that this is a case of "data rich, information poor". The third stance is most likely to be pupil-centred and to use pupils' perspectives on their experience. A thorough examination of the literature by Galton et al (1999) stated "our review suggests that the induction programmes energetically developed by schools in the 1980s and 1990s may have concentrated on the social aspects of transfer at the cost of establishing commitments to, and sound foundations for, academic learning." (page 11). It is not clear how such a division may be maintained if the social nature of learning and the collective nature of school life is recognised. Perhaps a later comment helps, when Galton et al (2000) write "Much of this research, however, has focused on the social adjustment of pupils to the change of school, rather than the impact of the school change on academic performance." (page 341). So the balance of research focus may be towards social matters, and the connection between this and other aspects of school purpose are still to be fully researched.

For the school in question, the results of the questionnaire led to an intervention being developed for the tutor group causing concern. The focus for intervention was chosen as a result of examining this group's scores on the dimensions of affiliation. It was noted that tutor group 7 scored the lowest on acceptance and respect. Given the great importance which the everyday language of these young people attach to "respect", this was chosen as the focus. The intervention was forged on two principles. The first was to treat respect as a relational phenomenon rather than a hierarchical, moral or formal phenomenon (Jones, 2002). The second was to adopt the stance of appreciative inquiry (Hammond, 1996) which aims to learn from and extend the best of pupils' experiences. The deputy Head of Year, 
was central in creating a plan for a single tutorial session, to be led by him and the form tutor. A skeleton outline is given below.

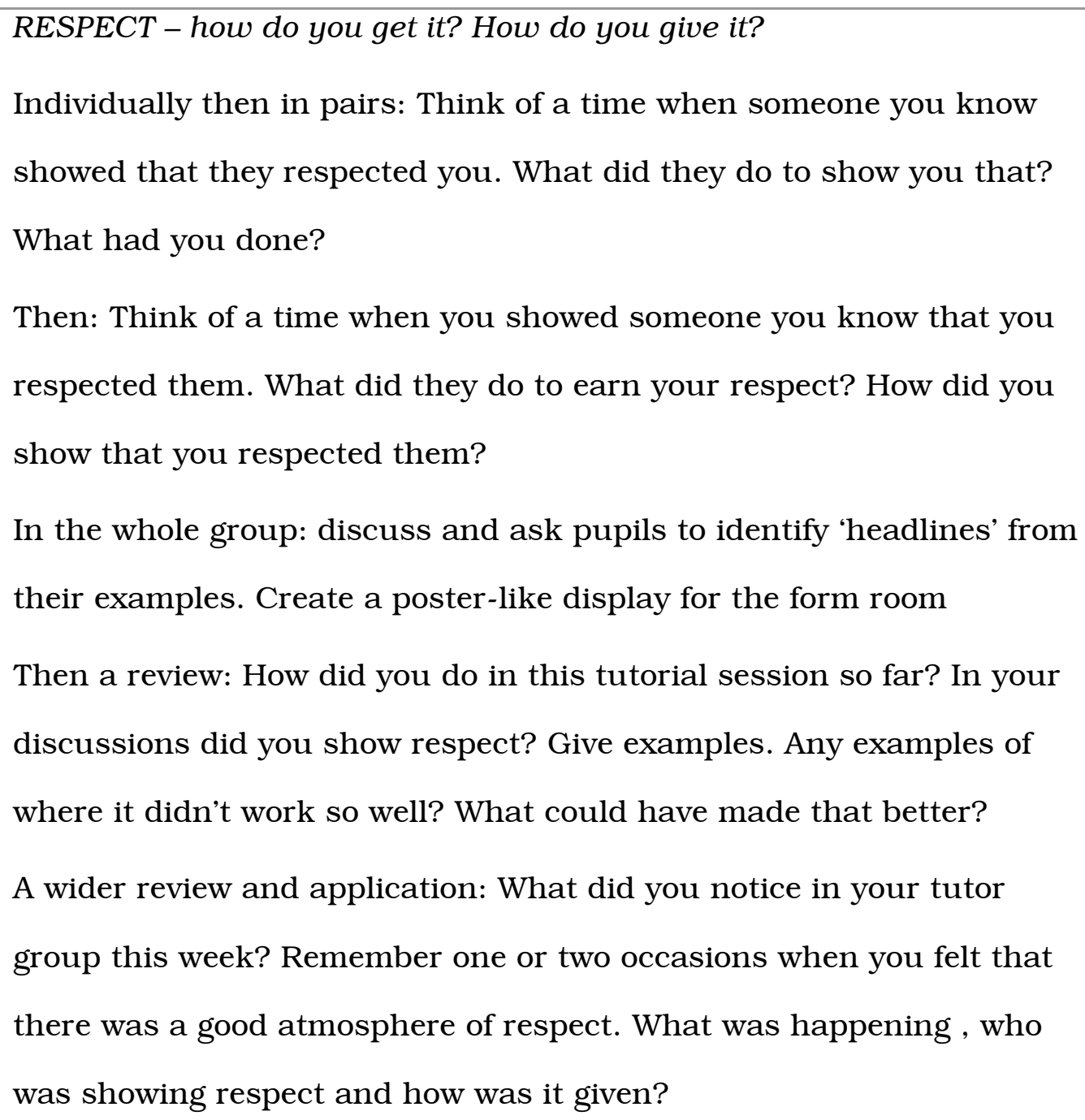

Tutors suggested that the session went broadly to plan, but was not completed in the time available.

Some three months later, pupils were asked to write a reflective review on "Settling in at ... School”. A number referred directly to the tutorial session:

“After a respect lesson that we had, everyone's very kind to each other. We all get on great. The respect lesson has also helped us to be much quieter in lessons that we have" (Elly)

"We had a lesson on respect in our class and it has changed a lot of people. They are much nicer and they treat you well. So if they treat you well you must treat them the same way" (Jade) 
"On the lesson of respect I learned to respect one and other by listening to

them. If I don't get any respect I feel real bad, so how could they feel?” (Jai)

The themes of reciprocality, empathy and interpersonal skill in these comments are very striking. It is also noticeable that the concept of respect is referred to in the relationships between pupils: complaints or comments about respect from teachers were not evident.

By the time the survey had been re-administered at the end of the school year, it was possible to compare scores by tutor group, both on the total affiliation score and on the separate dimensions. Tutor group 7 showed the largest gains on the respect dimension, and also on the acceptance dimension, moving from bottom scores in October to nearly top in July (see figure 3).

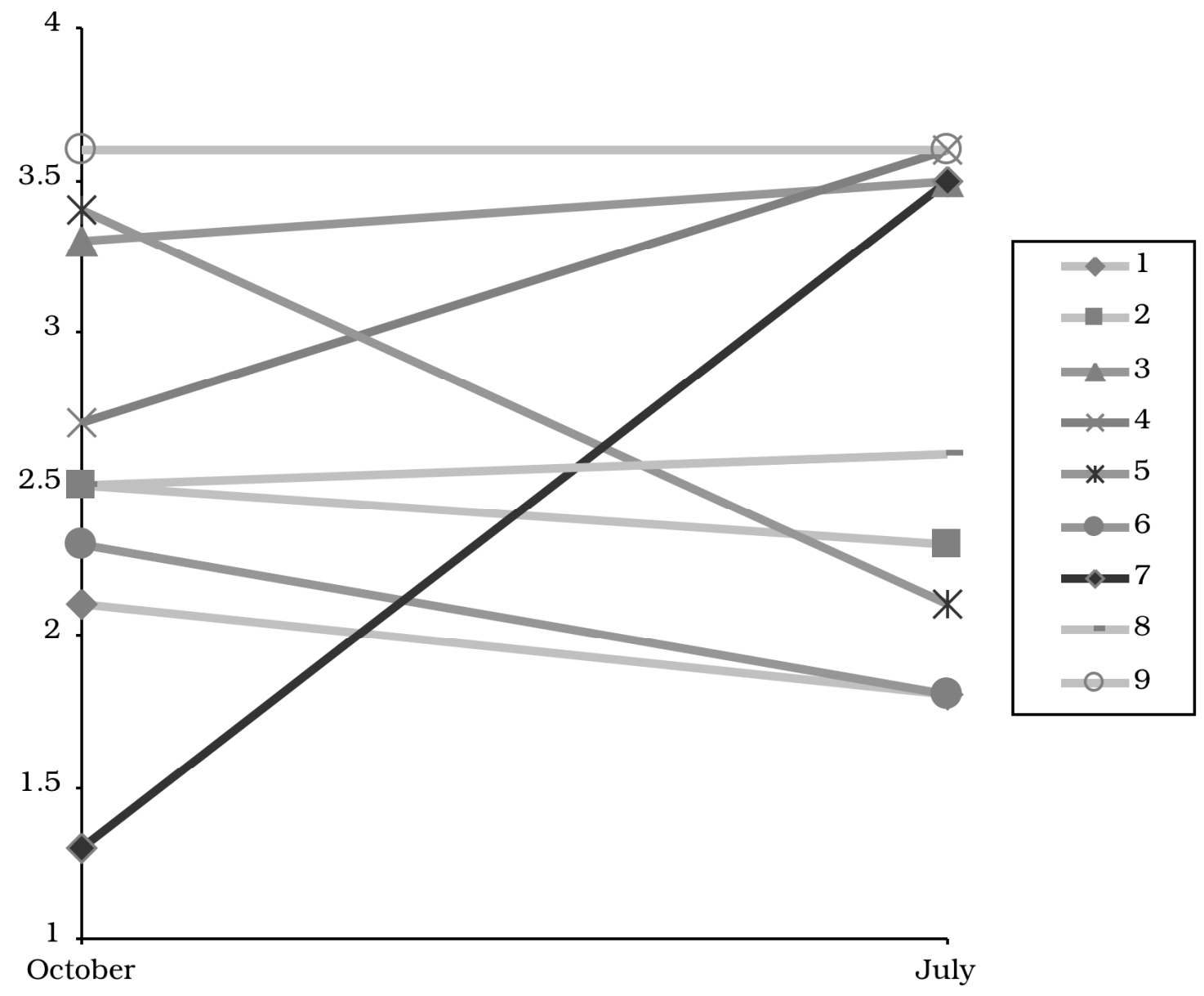

Figure 3: acceptance scores by the nine tutor groups, start and end of school year 
At a school staff development day the following school year staff reported that this tutor group had become more cohesive and prosocial. Three years later the tutor still reports that they are a prosocial and respectful group, but does not claim that this always makes them willing recipients of teacher-centred pedagogy.

The administration of the survey continued in following years, with the mean total for each cohort increasing within their year and increasing across years (see Table I). Table I also shows the mean scores on item 1 of the affiliation scale: "I feel like a real part of School". This too shows significant increases within each year cohort. Taken together, this seems like positive evidence of a steady upward trend in the overall stance of the school.

\begin{tabular}{|l|c|c|c|c|}
\hline Cohort & $\begin{array}{c}\text { Month of } \\
\text { measure }\end{array}$ & $N$ & mean total & mean item \\
\hline Cohort 1 & October & 246 & 12.9 & 1 \\
\hline Cohort 1 & July & 226 & 13.0 & 2.01 \\
\hline Cohort 2 & October & 232 & 13.1 & 2.09 \\
\hline Cohort 2 & July & 161 & 14.4 & 2.16 \\
\hline Cohort 3 & October & 164 & 14.3 & 1.98 \\
\hline Cohort 3 & July & 192 & 14.4 & 2.05 \\
\hline
\end{tabular}

Table I: Mean affiliation scores for three cohorts at two points in each year

\section{Discussion}

The broad contribution of this work seems to affirm the value of brief methods for eliciting pupils' views. Staff at the school received the results with interest, and required no convincing that their good practices can be honoured, and that problem areas identified by pupils can be addressed. This was not a fully developed school improvement project, with planned teamwork following the surveys, and therefore has the limitations associated with surveys done by outsiders. Better 
linkage to school improvement would doubtless come from school staff initiating and analysing the surveys.

Small interventions can have large impact if they are systemically effective, i.e.

- are well matched to the context and based on a real wish for change

- involve participants in mapping the current functioning and making new meaning

- become self-sustaining via feedback from the context

The tutorial intervention in this case seemed to reflect these conditions. It respected and did not disqualify pupils' voice on their experience of a key priority (see also Collins, 2000). It engaged pupils' agency in reporting appreciatively on their best experiences and making meaning of them (thus it escaped a common distortion of tutorial sessions which is to moralise). It put the culture of the group in the hands of the pupils.

In this sense it was an example of wider practices for developing learning communities (Horsch et al., 2000). It is not beyond the realms of possibility that putting the mechanisms for creating prosocial communities into the hands of pupils is the most powerful intervention a school can make.

Note

Special thanks are due to Caroline Whalley and John Parry for their parts in the initiation of this project, Hilary Belden for its continuation, and to the Year 7 tutors, team leaders and pupils.

\section{References}

AARÖ, L.E., WOLD, B., KANNAS, L. \& RIMPELÄ, M. (1986) Health behaviour in school children. A WHO Cross National Survey, Health Promotion International, 1 , pp. 17-33. 
ANDERMAN, L.H. \& ANDERMAN, E.M. (1999) Social predictors of changes in students' achievement goal orientations, Contemporary Educational Psychology, 25, 1, pp. 21-37.

COLLINS, J. (2000) Are you talking to me? The need to respect and develop a pupil's self-image, Educational Research, 42, 2, pp. 157-166.

GALTON, M., GRAY, J. \& RUDDUCK, J. (1999) The impact of transitions and transfers on pupil progress and attainment: DfEE Research Report RR 131 (Nottingham, DFEE Publications).

GALTON, M., MORRISON, I. \& PELL, T. (2000) Transfer and transition in English schools: reviewing the evidence, International Journal of Educational Research, 33, pp. 341-363.

GOODENOW, C. (1992) School Motivation, Engagement, and Sense of Belonging among Urban Adolescent Students (Paper presented at Annual Meeting of the American Educational Research Association, San Francisco, CA).

GOODENOW, C. (1993a) The psychological sense of school membership among adolescents: scale development and educational correlates, Psychology in the Schools, 30, 1 pp. 79-90.

GOODENOW, C. (1993b) Classroom belonging among early adolescent students: relationships to motivation and achievement, Journal of Early Adolescence, 13, pp. 21-43.

GOODENOW, C. \& GRADY, K.E. (1993) The relationship of school belonging and friends values to academic motivation among urban adolescent students, Journal of Experimental Education, 62, 1, pp. 60-71.

HAGBORG, W. (1994) An exploration of school membership among middle-school and high-school students, Journal Of Psychoeducational Assessment, 12, 4, pp. 312-323.

HAGBORG, W. (1998) An investigation of a brief measure of school membership, Adolescence, 33, 130, pp. 461-468. 
HAMMOND, S.A. (1996) The Thin Book of Appreciative Inquiry (Bend OR,

thinbook.com).

HORSCH, P., CHEN, J.-Q. \& NELSON, D. (2000) Rules and rituals: tools for creating a respectful, caring learning community, Phi Delta Kappan, 81, 3, pp. 223227.

JONES, H.M.F. (2002) Respecting respect: exploring a great deal, Educational Studies, 28, 4, pp. 341-352.

KUH, G.D. (2001) The National Survey of Student Engagement: Conceptual Framework and Overview of Psychometric Properties (Bloomington IN, Indiana University Postsecondary Research and Planning).

LEE, V.E. \& SMITH, J.B. (1993) Effects of school restructuring on the achievement and engagement of middle-grade students, Sociology of Education, 66, 3, pp. 164187.

ORGANISATION FOR ECONOMIC CO-OPERATION AND DEVELOPMENT (2001)

Knowledge and Skills for Life: first results from the OECD "Programme for

International Student Assessment” (PISA) 2000 (Paris, OECD).

ROESER, R., MIDGLEY, C. \& URDAN, T. (1996) Perceptions of the school psychological environment and early adolescents' psychological and behavioral functioning in school: The mediating role of goals and belonging, Journal of Educational Psychology, 88, 3, pp. 408-422.

SAMDAL, O., WOLD, B. \& BRONIS, M. (1999) Relationship between students' perceptions of school environment, their satisfaction with school and perceived academic achievement: An international study, School Effectiveness and School Improvement, 10, 3, pp. 296-320.

VOELKL, K. (1996) Measuring students' identification with school, Educational and Psychological Measurement, 56, 5, pp. 760-770.

VOELKL, K. (1997) Identification with school, American Journal Of Education, 105, 3, pp. 294-318. 
WATKINS, C. (1983) Sociological and psychological factors of transfer (paper presented at "Changing school : the problems of transition": the March Education Conference, Goldsmiths College London).

WATKINS, C. (1989) Your New School: Tutorial Resources for Year One (Harlow, Longman).

WATKINS, C. (2005) Classrooms as Learning Communities: what's in it for schools (London, FalmerRoutledge).

WILLMS, J.D. (2003) Student Engagement at School: a Sense of Belonging and Participation. Results from PISA 2000 (Paris, OECD: Organisation for Economic CoOperation and Development). 